\title{
Linguistic and racial re-formation of indigenous Mexicans' languages and races in Florida Heartland K-12 schools
}

\author{
Rebecca Campbell-Montalvo*
}

\begin{abstract}
I interrogate how consequential representations of student characteristics are fashioned by analyzing identification, recording, and reporting of student and parent language, race, and ethnicity in K-12 school registration, school records, and state reporting. In the Florida Heartland, analysis of ethnographic school observations, school electronic records, a language inventory (survey), interviews, and official state data show that language, race, and ethnicity information for some K-12 students and parents (especially indigenous Mexicans) collected during enrollment are not recorded accurately and undergo transformation from collection to reporting. According to my language inventory, students' parents were indigenous language speakers 19 times more often than reflected in raw school records. In records from the local middle school, 10 percent of students were American Indian, though the state reported this as 0 percent. This linguistic and racial re-formation resulted from several factors, including registrars recording languages as others (i.e. Spanish instead of Náhuatl), differential questioning practices, and state reporting policy. As discussed, enhanced procedures and updated policy should improve areas affected by inaccurate data.
\end{abstract}

Keywords. educational research methods; ethnicity; raciolinguistic ideologies; Latinization; QuantCrit

1. Introduction. Student demographic information, such as language, race, and ethnicity, is consistently quantified in US educational institutions after it is gathered during school registration. Representations of this demographic information are then used in a myriad of consequential ways, including during making decisions on affirmative action programs, investigations into school segregation (NCES 1996; Renn 2009), balancing classrooms, investigations of discrimination in ability grouping (Lopez 2003a; Vizcarra 2017), federal and state reporting of student progress by aggregated sub-groups, screening children for language services, informing culturally sustaining pedagogies (Paris and Alim 2014), and accessibility in school-home communication. Prior research has examined issues surrounding school registration interactions and the subsequent quantification of student characteristics (e.g., Baquedano-López 2019; Campbell and Castañeda 2019; Lopez 2003a; Lopez 2003b; Mendoza-Denton 2008; Renn 2009; Vizcarra 2017). Yet none highlight the important site of the on-the-ground micro processes that occur during school registration, tracing it all the way to codified reporting at the state level, as the present study does.

In investigating how representations of student and parent language, race, and ethnicity are constructed by schools and the state, I introduce the terms 'linguistic re-formation' and 'racial reformation' as theorization tools. With roots in Omi and Winant's (1986) 'racial formation', the terms respectively describe the processes of transformation that characteristics (i.e. language, race, and ethnicity) reported by students and parents may undergo by the time the information is used at school or in state reports. With this in mind, this study showed:

\footnotetext{
* Rebecca Campbell-Montalvo, University of Connecticut (rebecca.campbell@uconn.edu).
} 
- Linguistic re-formation occurred during observations of registration interactions, resulting in school system records that did not adequately capture the linguistic diversity of parents and students shown in the researcher's language inventory;

- Racial re-formation ensued from choices made on the school, county, state, and federal levels about how race/ethnicity are reported, which painted less-representative portraits of students' racial and ethnic characteristics in comparison to raw student records.

In couching my theorization tools, Omi and Winant's 'racial formation' highlights how political, economic, and social forces, especially state institutions, play a central role in constructing and implementing racial and ethnic categorizations and definitions (1986). Racial formation occurs through unequal social structures and hegemonic ideologies benefitting those in power. Socialization reifying these ideologies influences how groups are defined via institutions (Baker 1998). However, 'racial formation' dissociates "race from colonialism, liberalism, capitalism, and democracy" and curates "a sociology that forecloses the significance of racial social ontologies" (Hesse 2016:ix). The framework has thus played a vital role in scholarship that has ignored anti-blackness as a major factor in social structure-resulting in "conceptual aphasia," which refers to the ineffability that comes from denying historical and present trauma and structural inequality rooted in the US enslavement of Africans (Saucier and Woods 2016). Using 'racial formation' as a springboard for 'linguistic re-formation' and 'racial re-formation' allows a needed focus on institutional processes that shape how language, race, and ethnicity are measured, categorized, and quantified. I recognize both the critiques and utilities of 'racial formation' (Golash-Boza 2013).

I extend Omi and Winant's work to examine how language identifications are made and definitions of language are constructed during school registration. Here, the hegemonic processes through which languages are (re)grouped are underscored by ideas about how language and people are related, known as language ideologies (Errington 1999; Silverstein 1979; Woolard 1998). A specific set of language ideologies is especially applicable to findings in this study and in relation to linguistic re-formation: raciolinguistic ideologies (Flores and Rosa 2015). Here, the social positioning of ethnoracially-minoritized groups influences how others perceive their language. In this case, others often embody a white listening subject (Inoue 2016) that favors monolingualism. The outcome of raciolinguistic ideologically informed linguistic re-formation can be 'erasure', when descriptions and information relating to sociolinguistic phenomena or languages renders people invisible (Irvine and Gal 2000).

Additionally, the QuantCrit approach to analysis (Gillborn, Warmington, and Demack 2018) allows the articulation of how racial re-formation occurs. QuantCrit applies Critical Race Theory (CRT) to quantitative data in order to question how that data came to be. CRT has challenged claims of neutrality and objectivity in educational data for decades (Ladson-Billings and Tate 1995). Gillborn, Warmington, and Demack (2018) argue that research that has a goal of highlighting racial inequality often only presents correlations of race with negative outcomes, such as low achievement, rather than explaining how historical and current discrimination bare such inequality. The principles of QuantCrit are "the centrality of racism, [that] numbers are not neutral, [that] categories are neither 'natural' nor given: for 'race' read 'racism', [in] voice and insight: data cannot 'speak for itself', [and that we can and should be] using numbers for social justice” (Gillborn, Warmington, and Demack 2018: 169). In this study, I use a QuantCrit perspective to conceptualize racial re-formation (and linguistic re-formation) as existing due to broader historical and structural inequality and discrimination that specifically affects how people are represented in records. 
2. Linguistic re-formation: Methods, data, and findings. This study was conducted in a central Florida county I anonymize as Central County. It is part of the Florida Heartland, an area of six counties that has been described as more culturally similar to the Deep South than other parts of Florida. Agriculture draws migrant farmworkers to the area. Tejanos first arrived in the 1950s, but more recently Mexicans, including indigenous Mexicans, have been arriving directly from Mexico, some on H-2A Visas. The area is heavily conservative, as Republican candidates earn twice as much votes as Democratic candidates. The county's roots are religious, as more than half of locals attend services weekly. The area can also be described as economically depressed, given the low per capita income (around \$16,000).

There are five elementary schools, one middle school, and one high school in the public school district, which serves 5,300 students. There is a high rate of economically disadvantaged students (79\%). Nearly 40 percent of children live in a home where a language other than English is spoken. Central's body of mostly white teachers is in stark contrast to the student body, which is about 61 percent Latino, 30 percent white, and 6 percent black. These county and student characteristics provide a context of reception that immigrants and others not comprising the majority navigate as they seek education. Jackson et al. (2012), Campbell (2016), and Campbell-Montalvo and Castañeda (2019) provide further context on Central and its schools.

To highlight linguistic re-formation, I draw on ethnographic observations I conducted in two Central elementary school offices. Interactions between school employees and families during school enrollment processes revolved around getting the school registration form completed. Registrars sometimes filled out the form by asking parents questions or using their perceptions based on conversation with the family, other times the form was given to parents to fill out. At one school, Apple, there was not always a Spanish interpreter available though at the other school, Emerald, there was almost always an interpreter available.

A primary cause of linguistic re-formation found during observations was non-standard questioning practices used by registrars. The below excerpt shows the dialogue of a registration.

Office worker: For race?

Young woman: We put white. It's the closest thing.

Office worker: The closest thing....are there any records from the prior school? Where was it located?

Young woman: No records, they would be in Palestine, West Bank.

Office worker: Does he speak English?

Young woman: 'Hi, bye, ABCs, numbers...'

Office worker: What language?

Young woman: Arabic.

Note the types of language questions asked of the Palestinian multilingual family ("Does he speak English?" and "What language?"). In other cases, families, often appearing Latino, would be asked "Spanish, right?" instead of "Does he speak English?" or "What language?"

The second cause of linguistic re-formation involved families that registrars may have perceived to be Latino. When parents noted that they spoke indigenous Mexican languages, such as Náhuatl, "Spanish" was recorded on the form. Yet when the sister who spoke for the family in the earlier example responded, "Arabic," "Arabic" was written on the form. After I observed the re-forming of Náhuatl into Spanish, I was instructed by registrars that "Spanish" should be written on the form if any "language down there" (referring to Mexico) was reported.

These two causes of linguistic re-formation are likely informed by raciolinguistic ideologies or assumptions about one's language due to their perceived race. Here, registrars appeared to 
make preconceived judgements about student and parent languages based on their appearance, which impacted the types of questions they were asked and how their language was recorded.

To determine how widespread linguistic re-formation caused by the use of differential questioning practices and the re-forming of indigenous languages as Spanish was in school system data, I procured de-identified student data with administrator permission. This data was created by school employees based on completed school registration forms. To evaluate the accuracy of the school system data, I conducted a language inventory with students at the two Central elementary schools as well as the county's middle school (CJH). The language inventory responses provided data to compare to school records. About 2,000 inventories were distributed to students to take home and 1,287 were completed. The inventory was available in English on one side and Spanish on the other. It asked about the languages spoken by the child's parents as well as the student; see Campbell (2016) for more on the methodology behind the school system data and the language inventory.

Analyses of school records showed much less language variation than that shown in the language inventory. Importantly, the electronic records system only allowed one total language to be listed for a student's parents, preventing the school from recording multilingual abilities of parents. Yet, the language inventory showed that 56 percent of parents were monolingual, 42 percent were bilingual, and 2 percent were trilingual. For students, 50 percent of students were monolingual, 46 percent were bilingual, and 3 percent were trilingual. Additionally, a quarter of parents did not indicate that they spoke English, though 104 of those parents were multilingual. Tables 1 and 2 illustrate the differences between school records and the language inventory in terms of the amount of language variation identified by each. Table 1 shows the language spoken by parents and the language spoken in the home for students, according to school records. Table 2 shows the language spoken by students, mothers/parent 1 , and fathers/parent 2 , according to the language inventory. One reason that the total numbers of languages reflected in Table 2 are higher is because respondents could select more than one language on the language inventory.

\begin{tabular}{lllllll} 
& \multicolumn{2}{c}{ Apple } & \multicolumn{2}{c}{ Emerald } & \multicolumn{2}{c}{ CJH } \\
Language & Parent Home & Parent & Home & \multicolumn{2}{c}{ Parent Home } \\
\hline Spanish & 225 & 154 & 166 & 172 & 450 & 430 \\
English & 149 & 221 & 96 & 120 & 63 & 78 \\
Haitian Creole & 10 & 5 & 0 & 0 & 4 & 4 \\
Hmong & 3 & 1 & 2 & 3 & 2 & 1 \\
Mixtec & 0 & 0 & 2 & 2 & 2 & 1 \\
Arabic & 2 & 2 & 0 & 0 & 1 & 1 \\
Indian & 1 & 0 & 0 & 0 & 2 & 2 \\
Vietnamese & 1 & 0 & 0 & 0 & 1 & 1 \\
Bengali & 0 & 0 & 0 & 0 & 1 & 1 \\
Chinese & 0 & 0 & 1 & 1 & 0 & 0 \\
Gujarati & 1 & 1 & 0 & 0 & 0 & 0 \\
Laotian & 0 & 0 & 0 & 1 & 0 & 0 \\
Romanian & 1 & 0 & 0 & 0 & 0 & 0 \\
Missing & 174 & 183 & 122 & 90 & 474 & 481 \\
\hline Total & 567 & 567 & 389 & 389 & 1000 & 1000 \\
\hline
\end{tabular}

Table 1: Parent and home language based on school records. 


\begin{tabular}{|c|c|c|c|c|c|c|c|c|c|}
\hline \multirow[b]{2}{*}{ Language } & \multicolumn{3}{|c|}{ Apple } & \multicolumn{3}{|c|}{ Emerald } & \multicolumn{3}{|c|}{$\mathrm{CJH}$} \\
\hline & $\mathrm{S}^{*}$ & $\mathrm{M}^{*}$ & $\mathrm{~F}^{*}$ & $\mathrm{~S}$ & M & $\mathrm{F}$ & $\mathrm{S}$ & M & $\mathrm{F}$ \\
\hline English & 278 & 218 & 213 & 231 & 157 & 147 & 746 & 587 & 588 \\
\hline Spanish & 128 & 168 & 171 & 141 & 175 & 187 & 331 & 435 & 435 \\
\hline Mixtec & 4 & 7 & 5 & 4 & 22 & 20 & 7 & 18 & 18 \\
\hline ASL & 2 & 5 & 1 & 2 & 3 & 2 & 17 & 8 & 3 \\
\hline Haitian Creole & 6 & 6 & 5 & 0 & 0 & 0 & 7 & 8 & 10 \\
\hline Hmong & 3 & 4 & 3 & 2 & 3 & 3 & 5 & 7 & 6 \\
\hline Zapotec & 0 & 0 & 0 & 4 & 6 & 8 & 1 & 2 & 3 \\
\hline French & 1 & 3 & 2 & 0 & 1 & 0 & 3 & 5 & 3 \\
\hline Arabic & 3 & 3 & 2 & 0 & 1 & 0 & 0 & 1 & 0 \\
\hline German & 0 & 0 & 1 & 0 & 1 & 0 & 3 & 2 & 3 \\
\hline Náhuatl & 0 & 1 & 3 & 0 & 1 & 1 & 0 & 1 & 1 \\
\hline Romanian & 0 & 0 & 1 & 1 & 0 & 1 & 2 & 1 & 2 \\
\hline MSL & 0 & 0 & 0 & 0 & 2 & 2 & 1 & 1 & 1 \\
\hline Bajo & 0 & 0 & 0 & 0 & 3 & 3 & 0 & 0 & 0 \\
\hline Gujarati & 1 & 1 & 1 & 0 & 0 & 0 & 1 & 1 & 1 \\
\hline Mamascol & 0 & 0 & 0 & 2 & 2 & 2 & 0 & 0 & 0 \\
\hline Trique & 0 & 0 & 0 & 0 & 2 & 2 & 0 & 0 & 0 \\
\hline Bengali & 0 & 0 & 0 & 0 & 0 & 0 & 1 & 1 & 1 \\
\hline Huasteco & 1 & 1 & 0 & 0 & 0 & 0 & 0 & 0 & 0 \\
\hline Lao & 0 & 0 & 0 & 0 & 0 & 1 & 0 & 0 & 1 \\
\hline Malay & 0 & 0 & 0 & 0 & 1 & 1 & 0 & 0 & 0 \\
\hline Alto & 0 & 0 & 0 & 1 & 0 & 0 & 0 & 0 & 0 \\
\hline Cerean & 0 & 1 & 0 & 0 & 0 & 0 & 0 & 0 & 0 \\
\hline Greek & 0 & 0 & 0 & 0 & 0 & 0 & 0 & 0 & 1 \\
\hline Honduran & 0 & 0 & 0 & 0 & 0 & 0 & 0 & 0 & 1 \\
\hline Italian & 0 & 0 & 1 & 0 & 0 & 0 & 0 & 0 & 0 \\
\hline Latin & 0 & 0 & 1 & 0 & 0 & 0 & 0 & 0 & 0 \\
\hline Otomi & 0 & 0 & 0 & 0 & 1 & 0 & 0 & 0 & 0 \\
\hline Tarasco & 0 & 0 & 0 & 0 & 0 & 0 & 0 & 0 & 1 \\
\hline Vietnamese & 0 & 1 & 0 & 0 & 0 & 0 & 0 & 0 & 0 \\
\hline Missing & 2 & 1 & 5 & 2 & 4 & 4 & 1 & 1 & 7 \\
\hline Total & 427 & 419 & 410 & 388 & 381 & 380 & 1125 & 1078 & 1079 \\
\hline
\end{tabular}

*S=Student, M=Mother/Parent 1, F=Father/Parent 2

Table 2: Student, mother/parent 1, and father/parent 2 languages based on language inventory.

As the tables illustrate, indigenous Mexican and other languages were grossly under identified in school records compared to the language inventory. In school records, only 13 languages were listed for parents while 30 languages were listed in the language inventory. Further, several indigenous Mexican languages identified in the inventory, including Bajo, Huasteco, Náhuatl, Otomi, Tarasco, Trique, and Zapotec, were not found in school records. In school records, 0.3 percent of student parents were shown to speak an indigenous Mexican language, while 5.7 percent of students had a parent who spoken an indigenous Mexican 
language on the language inventory. Thus, the language inventory shows that students' parents spoke an indigenous Mexican language 19 times more often than shown in school records.

Just as observations showed that differential questioning techniques were used for various families, analysis of school records found that certain students (Asian, Latino, and American Indian students) were more likely to have language information in their records than other students (white and African American students). Specifically, white students had no information in any of the language columns in the electronic records system 64 percent of the time, followed by black students (55\% missing), multiracial students (52\%), Latino students (19\%), Asian students (11\%), and American Indian students $(0 \%)$.

One explanation for the difference in the completion rate of school records pertaining to language for these groups is that white and African American students may have been assumed by school personnel to have higher rates of English proficiency or lower rates of speaking an additional language, and thus they may not have been asked the language questions during registration. It may be that registrars believed that Asian, Latino, and American Indian students were more likely to need language services, possibly due to raciolinguistic ideologies.

3. Racial re-formation: Methods, data, and findings. The second research goal dealt with the effects of race and ethnicity data tabulation on counts and representations of groups of people, especially critical given that individuals can belong to more than one group (Lopez 2003a; Lopez 2003b; Vizcarra 2017). How the county and state address the reporting of student/family race and ethnicity can cause institutional or macro racial re-formation. For example, students who were American Indian (10\% of CJH students) were not reported in this category in state records because most of the students were also Latino. It is FDOE policy that students counted in the Latino category are reported only in that category. This discrepancy of 10 percent vs. 0 percent of middle school students being American Indians illustrates the third principal in QuantCrit, which considers how numbers are not neutral, as 'even the most basic decisions in research design can have fundamental consequences for the re/presentation of race inequity' (Gillborn, Warmington, and Demack 2018:171).

Table 3 shows race and ethnicity of students at the three schools (Apple, Emerald, and CJH) calculated in three different ways. The first column (A) shows percentages of students in the major grouping categories used by FDOE (Latino, Asian, black, Pacific or Native Hawaiian Islander, white, American Indian, and multiracial). However, even though the same seven groupings are used, the way I calculated group membership in this column differed from FDOE rules. Specifically, I performed these calculations by counting students in all groups in which they are a member (e.g. Latino and Asian), according to the school electronic records. This is a non-exclusive type of reporting called "multiple group assignment tabulation method" where individuals may be counted in more than one category, if applicable (Lopez 2003a). In the second column (B), I used FDOE rules to perform calculations. In this category, Latinos are counted only in the Latino category even if they also claimed one or more races (e.g. Latino, not Asian). Students who were not Latino and selected more than one racial category were counted in the multiracial category. The third column (C) lists the FDOE data on the schools obtained directly from their website's School Accountability Public Reports section located at http://doeweb-prd.doe.state.fl.us/eds/nclbspar/index.cfm. I did not perform any calculations presented in this third column and it uses FDOE rules where Latinos are counted only as Latinos and in no other group. 


\begin{tabular}{llllllllll} 
& $\begin{array}{l}\text { A. Researcher Calculated } \\
\text { Using Non-Exclusive } \\
\text { Categories and Raw } \\
\text { School Electronic Data*** }\end{array}$ & $\begin{array}{l}\text { B. Researcher Calculated } \\
\text { Using FDOE Rules } \\
\text { and Raw School } \\
\text { Electronic Data*** }\end{array}$ & $\begin{array}{l}\text { C. Obtained from } \\
\text { FDOE Website using } \\
\text { FDOE Rules }\end{array}$ \\
\hline $\begin{array}{llllllllll}\text { Racial/Ethnic } \\
\text { Group }\end{array}$ & App. & Em. & CJH* & App. & Em. & CJH* & App. & Em. & CJH \\
\hline 1. Latino & $61 \%$ & $81 \%$ & $64 \%$ & $61 \%$ & $81 \%$ & $64 \%$ & $61 \%$ & $80 \%$ & $61 \%$ \\
2. Asian & $2 \%$ & $3 \%$ & $1 \%$ & $1 \%$ & $2 \%$ & $1 \%$ & $1 \% * *$ & $1 \% * *$ & $0 \% * *$ \\
3. Black & $11 \%$ & $2 \%$ & $7 \%$ & $7 \%$ & $2 \%$ & $5 \%$ & $7 \%$ & $1 \% * *$ & $6 \%$ \\
4. Haw. Isl. & $0 \%$ & $0 \%$ & $1 \%$ & $0 \%$ & $0 \%$ & $0 \%$ & $0 \%$ & $0 \%$ & $0 \%$ \\
5. White & $89 \%$ & $92 \%$ & $84 \%$ & $28 \%$ & $15 \%$ & $30 \%$ & $29 \%$ & $17 \%$ & $31 \%$ \\
6. Amer. Ind. & $3 \%$ & $5 \%$ & $10 \%$ & $0 \%$ & $0 \%$ & $0 \%$ & $1 \% * *$ & $0 \%$ & $0 \% * *$ \\
7. Multiracial & $5 \%$ & $1 \%$ & $3 \%$ & $2 \%$ & $1 \%$ & $2 \%$ & $2 \%$ & $1 \% * *$ & $2 \%$ \\
Total \# & 567 & 389 & 1000 & 567 & 389 & 1000 & 547 & 373 & 1209 \\
\hline
\end{tabular}

*Data available for first 1000 of 1,388 students listed alphabetically.

** Groups numbered $<10$ but $\geq 1$; estimates calculated using mean of range of possible values. ***Percentages add up to more than 100 due to rounding and estimation for small groups.

Table 3: Student race and ethnicity calculated with raw records and reported by FDOE.

As can be seen, a different portrait of student demographics is painted when comparing the two different strategies (multiple group assignment [column A] vs. FDOE rules where Latinos are counted only in that group [column B]). Similar to how linguistic re-formation erased indigenous Mexican languages, Latinos' American Indian racial statuses were erased via racial re-formation. For instance, consider the sixth race/ethnicity group row listed in Table 3: American Indian. In the multiple group assignment calculations (column A), American Indians comprised 3 percent of the students at Apple, 1 percent at Emerald, and 10 percent at CJH. Those numbers dropped to 0 percent for all three schools in column B, in which I use FDOE's rules where Latino students are counted only in that category and not in any racial categories that they may have selected.

It is important to note that this racial re-formation is not limited to indigenous Latino students, who other data showed were mostly indigenous Mexicans. Table 3 shows that in the multiple group assignment calculations (column A), black students were also affected by racial re-formation. Here, black students comprised 11 percent of the student body at Apple, 2 percent at Emerald, and 7 percent at CJH. Those numbers dropped to 7 percent of the student body at Apple, 2 percent at Emerald, and 5 percent at CJH in column B, which uses FDOE's rules counting Latinos as distinct from any racial groupings.

In Table 3, column $\mathrm{C}$ contains slightly different numbers than those in column B even though they use the same computation rules and are from the same year and same schools. This difference likely stems from the time when I obtained the raw data I calculated, which was at the end of the 2014-2015 school year and prior to withdrawals being removed from the system, according to registrars. Column $\mathrm{C}$ used state data that came from figures reported by schools on October enrollment, which is near the start of the school year. Importantly, October membership data is actually collected before many migrant farmworkers return to the area and re-enroll their children. However, some migrant children do remain enrolled at the beginning of the school year from last year even if they do not arrive back in central Florida until around November. 
4. Conclusion and applications. To follow the creation of student data from registration to reporting, I analyzed data from observations, the language inventory, raw school records, interviews, and state records. This allowed me to trace and compare different sources of student data that describes student and parent language, race, and ethnicity to interrogate the accuracy of the data and understand how it represented those it claims to represent. Building upon racial formation theory, I have shown how raciolinguistic ideologies, in part, spurred linguistic reformation. I also used a QuantCrit approach comparing how the racial and ethnic categories used by FDOE are defined and utilized to uncover racial re-formation. Students of color appeared disproportionately affected in terms of their data being re-formed, both in terms of linguistic reformation and racial re-formation. Unfortunately, this suggests that not all students receive the same language screening, that some students are more likely to have their languages erased from school records, and that some students are more likely to have their racial statuses erased from school records. This erasure puts equity at risk, given the multiple ways that such demographic data is used.

To address the linguistic re-formation that was observed, I recommend that schools offer training specific to the registration process as well as cultural competency training. All families should be asked the same questions in the same manner and all languages reported by families should be recorded verbatim. This may entail updates to the school's electronic records system to allow multilingual abilities to be inputted. Likewise, to mitigate racial re-formation in reporting of student race and ethnicity, I suggest that complementary reporting of race and ethnicity statuses be used. For instance, going back to Table 3, if both methods employed in columns A and $\mathrm{B}$ are used, a more complete and nuanced understanding of students may be achieved.

Further research should be conducted to understand how widespread linguistic and racial reformation are in schools in additional areas and contexts. We must pay special attention to how school demographic data is constructed given that the majority of studies on groups in education use such data to inform conclusions and the specific ways that the data is tabulated and gathered impact findings (Brown and De Lissovoy 2011; Gillborn, Warmington, and Demack 2018; Lopez 2003b).

\section{References}

Baker, Lee. 1998. From savage to Negro: Anthropology and the construction of race, 18961954. Los Angeles: University of California Press.

Baquedano-López, Patricia. 2019. Indigenous Maya families from Yucatan in San Francisco: Hemispheric mobility and pedagogies of diaspora. In Shannon Gleeson \& Xóchitl Bada (eds.), Accountability across borders: Migrant rights in North America. 515-563. Austin, TX: University of Texas Press.

Brown, Anthony \& Noah De Lissovoy. 2011. Economies of racism: Grounding education policy research in the complex dialectic of race, class, and capital. Journal of Education Policy 26(5). 595-619.

Campbell, Rebecca. 2016. Reification, resistance, and transformation? The impact of migration and demographics on linguistic, racial, and ethnic identity and equity in educational systems: An applied approach. Tampa, FL: University of South Florida dissertation. http://scholarcommons.usf.edu/etd/6474.

Campbell-Montalvo, Rebecca \& Heide Castañeda. 2019. School employees as health care brokers for multiply-marginalized migrant families. Medical Anthropology. https://doi.org/10.1080/01459740.2019.1570190. 
Errington, Joseph. 1999. Ideology. Journal of Linguistic Anthropology 9. 115-118.

Flores, Nelson \& Jonathan Rosa. 2015. Undoing appropriateness: Raciolinguistic ideologies and language diversity in education. Harvard Educational Review 85. 149-171.

Gillborn, David, Paul Warmington, \& Sean Demack. 2018. QuantCrit: Education, policy, 'big data' and principles for a critical race theory of statistics. Race Ethnicity and Education 21(2). 158-179.

Golash-Boza, Tanya. 2013. Does racial formation theory lack the conceptual tools to understand racism? Ethnic and Racial Studies 36(6). 994-999.

Hesse, Barnor. 2016. Preface: Counter-racial formation theory. In P. Kahlil Saucier \& Tyron

P. Woods (eds.), Conceptual aphasia in black: Displacing racial formation. New York: Lexington Books.

Inoue, Miyako. 2006. Vicarious language: Gender and linguistic modernity in Japan. Berkeley: University of California Press.

Irvine, Judith \& Susan Gal. 2000. Language ideology and linguistic differentiation. In Paul Kroskrity (ed.), Regimes of language. 35-83. Santé Fe: School of American Research Press.

Jackson, Antoinette, Margaret Allsopp, Kiersten Downs, \& Meredith Main. 2012. Rapid ethnographic assessment. Retrieved from https://goo.g1/qpjGxf.

Ladson-Billings, Gloria \& William Tate. 1995. Toward a critical race theory of education. Teachers College Record 97(1). 47-68.

Lopez, Alejandra. 2003a. Mixed-race school-age children: A summary of census 2000 data. Educational Researcher 32(6). 25-37.

Lopez, Alejandra. 2003b. Collecting and tabulating race/ethnicity data with diverse and mixed heritage populations: A case-study with US high school students. Ethnic and Racial Studies 26(5). 931-961.

Mendoza-Denton, Norma. 2008. Homegirls: Language and cultural practice among Latina youth gangs. Oxford: Wiley Blackwell.

NCES. 1996. Racial and ethnic classifications used by public schools. Statistical analysis report. Washington, DC: National Center for Education Statistics.

https://nces.ed.gov/pubs/96092.pdf.

Omi, Michael \& Howard Winant. 1986. Racial formation in the United States. New York:

Routledge.

Paris, Django \& H. Samy Alim (eds.). 2017. Culturally sustaining pedagogies: Teaching and learning for justice in a changing world. New York: Teachers College Press.

Renn, Kristen. 2009. Educational policy, politics, and mixed heritage students in the United States. Journal of Social Issues 65(1). 165-183.

Saucier, P. Kahlil \& Tyrone P. Woods (eds.). 2016. Conceptual aphasia in black: Displacing racial formation. New York: Lexington Books.

Silverstein, Michael. 1979. Language structure and linguistic ideology. In Paul Clyne, William Hanks \& Carol Hofbauer (eds.), The elements, a parasession on linguistic units and levels. 193-247. Chicago: Chicago Linguistic Society.

Vizcarra, Margarita. 2017. 'Creating a new mythos': Reassessing race standards and Latina/o students. Chicago, IL: Loyola University Chicago thesis.

Woolard, Kathryn. 1998. Language ideology as a field of inquiry. In Bambi Schieffelin, Kathryn Woolard \& Paul Kroskrity (eds.), Language ideologies: Practice and theory. Oxford: Oxford University Press. 